\title{
Principles in the African Community/Culture with Special Reference to the Tsonga Community and the Dimensions of Child Development in the Foundation Phase
}

\author{
Swanki Stephinah Senosi
}

Department of Early Childhood Education, University of South Africa

Doi:10.5901/mjss.2014.v5n23p2211

\begin{abstract}
Absract
The study is qualitative in nature and it examines the principles in the African community and the dimensions of child development in the Foundation Phase. Data for this paper was collected from the parents of the Grade Two learners in a township school. The main aim was to get to know how Africans live and the support they provide to their children during the Foundation Phase period, which was mainly based on the Tsonga culture. Africans in general, need to keep abreast with what is happening in the daily lives of their children in order to effectively take part in their education.
\end{abstract}

\section{Introduction}

During the early years, the African child receives lenient and patient treatment. As the child grows older, he is made to be less dependent on the mother and other members of the family. The gradual gaining of independence by the child is encouraged by his/her increasing mobility and the eakening of the bond between mother and child.

Africans feed on maize-meal. This cereal is cultivated in almost all African communities, especially in rural areas. It is sown and harvested easily. At Christmas time, when the first cobs are edible, people joyfully feast on the new crop. They cook some of them in the ashes, but they allow some of the rest to ripen and dry upon the stalks to make mieliemeal. Children are fed on soft porridge from three months until they are eighteen months old. Next important comes the "mabele", commonly known as "kafir corn".

It is pounded and may be eaten in the form of "bogobe", known as "bupi" or flour. According Sebidi (1999:39), "kafir corn" takes a longer time to prepare. The grains must first besoaked for several hours in water to soften them. They are then crushed, the husks being carefully removed by the winnowing process (fefera) in the basket, which is spasmodically shaken with sudden jerky movements. The kernel of the grain is then pounded until it forms a fine "bupi" flour.

In the African communities, the vegetables are mainly "morogo" or spinach, sweet potatoes and pumpkins. According to Junod (1962, in Sebidi 1999:41), the leaves of the sweet potatoes are sometimes used as a vegetable. Meat, milk and eggs are seldom given to children. In some families meat is used once or twice a week which may cause inadequacies in the growing children. Diet and health are closely related. It can be argued that the diet of children is of direct relevance to their intellectual development and capability. For this reason, Mwamwenda (1995:31) contends that the food consumed by children must contain all the essential food nutrients such as proteins, carbohydrates, vitamins, water, fat and minerals. All children must have a balanced diet.

African societies show an unusual problem with regard to health decisions, in that they have to consider whether to adopt a western or traditional health system, or a combination of both. This can leave the family in a state of conflict, because of the question whether the traditional or western approach would be the best to address a particular health problem. Pienaar and Spoelsra (1991:24) declare that, although Africans generally acknowledge the reality of the social forces that have set the stage for a more differentiated, more rationalised and a more individualised world, the continued vitality of traditional thought patterns about the meaning of health and illness cause some African families to experience uncertainty, confusion and conflict regarding choices between western and traditional methods of healing. Uncertainties, confusion and conflicts in the African community with regard to modern medicine, African herbal medicine or faith healing, may cause growing children to feel insecure and unsafe. Such treatment may ultimately act against each other, which in turn may cause misunderstanding in the haeling, and be detrimental to the child.

The African's perceptions about health are based on a broad ecological framework. Such percepyions are often difficult to understand from the perspective of the western approach. The African worldview offers a metaphysical approach, which is shared by the traditional healer and his/her clients (Bodibe 1990:120). The western approach, on the other hand, is characterised by the ever developing and improving scientific approach to treatment and a highly 
competitive level observed within the medical environment (Schlebush 1990:145). The western approach often appears impersonal and bureaucratic to the Afircan, thus making understanding it more diffcult for the traditional family.

Just as the family relationships can be our greatest source of nurturance and support, they can also be a powerful source of anguish. For example, if in the home a parent loses a job, the children's education may be affected because there would be a lack of money to buy school material. Poor housing, overcrowding and frequent clashes in the family may also be a source of anguish. Uncertaities may result in children being abused, starved, suffocated and sexually molested, which in turn may result in children becoming HIVIAIDS positive. According to Shaffer (1993:612), other children in African communities are not targets of these "physical" forms ofabuse but are victims of such psychological psychological abuse as being rejected, ridiculed or even terrorized by their parents.

The African child in the Foundation Phase demonstrates his semi-independence by doing things on his own, exercising his skills, refusing to be rigidly controlled and managed, exploring the environment starting to form relationships with other people outside the family, such as the peer group. This stage is problematic for parents and other family members as they strive to exercise control over the child. The aim of parents at this stage is to teach the child to control his behaviour and emotions and to create a conducive environment for the child.

\subsection{Physical dimension in Tsonga culture}

Among the Tsongas, few men stay with their families. The role of the man with regard to children in the family is to be an identification figure, to exercise control over the children, to discipline and guide them and be a figure of authority. Unfortunately, most of the Tsong families in the rural ares lack fathers, for the fathers stay with them for a shorter period because of migratory labour practices, divorce or desertion. Most of the men in Tsonga families marry more than one wife. If, for example, he marries three wives, two will be left in the rural area while the third one remains with him in the urban area.

In some families, the grandmother stays with the family and her influence is vast. Her influence over the child occurs in two ways: by indirectly influencing the attitudes and feelings of the parents towards the child, or by directly influencing the child. Outside the family, the peer group also influences the child. He learns to perceive the needs and responses of others and to respond to them accordingly. The responses may be positive or the child may show acquired negative attitudes, such as envy and or the child may show acquired negative attitudes, such as envy and rivalry. According to Mwamwenda (1995:34), the African boy (including the Tsonga) uses stick fights to be tested for leadership and courage while among girls the criterion is the ability to sing. The Tsonga women and girls are expected to learn domestic duties and become acquainted with agricultural work, while the boys at the age of seven to nine learn to tend the stock in the kraal and to herd them in the tribal lands.

The Tsongas give great attention to cooking. Of a woman who knows how to cook well, it is said: "A wa hisa", she burns (but not meant negatively). Junod (1962 in Sebidi 1999:36) declares that a girl who knows how to "hisa" will have more chance of being married. As a rule, women cook only once a day, towards the end of the afternoon. This is a big meal which is eaten in the evening when everybody is expected to eat till satisfied, and what remains of it is generally finished the next day in the morning. This evening mael consists of cooked cereals (bupi) and the sauces (seshebo) seasonong them, consisting of "morogo", tomatoes and salt boiled in water.

\subsection{General principles}

From the time children are weaned until they go to school, roughly between the ages of two and seven, the main pressure upon them in all societies is to learn to take care of themselves, and not to expect the kind of attention they received as babies. Much of their time is spent playing with siblings siblings in the house or close by, or in a child care centre. It is at this stage that children also learn to take care of physical routines independently.

Children in the Foundation Phase become less emotionally dependent and unstable. This is the time when they are ready for school, the time when they learn to deal with adults other than their parents. They feel safe at school even if their parents are not there and if a stranger scolds them, they are free to accept the situation. During the Foundation Phase, children grow into risk taking, they learn that at school there is no place for tantrums, and learn to be less dependent. They discover how they are accepted and how they perform compared with other children of their age.

Wyngaard (1994:58) declares that the child should be taught to understand the influence of emotions on his behaviour and his personal life, should learn how to control his emotions, and also be consciously aware of the dangers of uncontrolled emotional outburst. Wyngaard (1994:59) adds that it is especially the negative emotional manifestations such as anxiety, fear, antagonisn, irritation, moodiness and tantrums, which have dangerous repercussions for the child 
and his society during childhood. If these manifestations are ignored or merely accommodated without constructive control, emotional and behavioural patterns will be established in the child which he will find difficult to overcome in his later life.

Certain dominant values of a culture influence the way in which a parent responds to his/her child.

If love and warmth are important positive values for social interaction, these may govern a mother's behaviour towards her child, even though at the same time she may believe she is spoiling him.

Nhlapo (1997:19) declares that "... parents have to continuously strive to build emotional reserves in their children as it is of vital necessity for their education." Where children have a sense of security they explore their world more confidently and consequently learn better. Parents are strong pillars for supporting the lives and education of their children. Parents have to make sure that children's needs are satisfied. According to Miller (1981 in Cooper 1991:22), every child has a legitmate narcissistic need to be noticed, loved, understood, taken seriously and respected by his/her mother. Nhlapo (1997:19) adds that psychological needs are satisfied when children are aware that people have affection for them and accept them as members of the group. He furter emphasises that the need to belong is a most pwerful socialising force and compels the child to become agreeable to others and to assume an attitude of give-and-take in the group situation. Children also need proper housing conditions and food in order to feel loved and secure. During the Foundation Phase children socialize with other children at school and become able to form a support group. They have less fear that making mistakes others would laugh at hem. They become free and are aware that other children do love them too.

\subsection{Effect of problems/inadequacies}

Emotional instability is the result of feelings of fear, tension and uncertainty and it can be characterized by sensitivity, inner tension, and the call for attention, help and sympathy, and might even lead to depression. According to Wyngaard (1994:58), emotional neglect can lead to: detrimental effects on bodily growth; detrimental effects on the digestive system; lowering of resistance to illness; increasing susceptibility to asthmatic illness and skin irritations; and speech difficulties, such as stuttering.

Unhealthy emotional reserves may cause children to become stubborn. If in the family such as a situation arises, parents should take action and guide a child firmly to stop the habit. Parents who always take action against stubborn children, do so because they have love for them. If the child does not want to obey, the parent must firmly direct him to do the right thing. If the parent does not take action immediately, according to Cooper (1991:41), the child in this situation would probably grow up experiencing a deep sense of aloneness and a fear of intimacy. Cooper (1991:42) emphasises that in taking action against such behaviour, parents are shaping the development of the children's subjective and interpersonal world.

Children must be brought up in a stable and emotionally secure environment. One of the results of a child being deprived of affection in the early years is poor academic work at school (Cooper 1991:22).

Such children may be very intelligent, but they lack interest and do not seem to care what others think of them. According to Etaugh and Rathus (1995:19), those who have not been loved as children may be incapable of loving others as adults. They are said to be affectionless.

Failure of affective bonding interferes with basic tension control in very early infancy and results in either understimulation or overstimulation. Children who have experienced such damage, according to Cooper (1991:44), usually find productive or meaningful relationships very difficult and may display borderline personality structures. If children in the Foundation Phase are not given love and support by their parents, they may experience emotional problems. They might feel unsafe and start playing truant and throwing tantrums which might in turn affect their learning.

\subsection{Principles in the African community/culture}

Among the Africans, child-rearing is mainly the responsibility of the mother. The mother is always with the child from birth to maturity when the father is out at work. The child learns most from the mother. According to Matlou (1993:35), the child learns the language of his/her mother and the moral authority of the mother remains considerable. During the Foundation Phase, that is 6-9 years, a child confides in his/her mother when in trouble, hence the saying in black culture that "The mother holds the knife at its sharp end." This is why in the view of the African child, the mother is worth more than the father. She is the one who prepares her children for future life, the environment and the world they live in.

The mother, as explained earlier, is seen essentially as donor of life. The child becomes so close to so close to his mother that an insult to her will be deeply felt. The relation of children to their mothers takes on a very different coloration 
than to their fathers. In the domain of modesty and language, one very often finds a very great reserve between the children and their father and a very close connection with their mother (Matlou 1993:33). Children Children in the Foundation Phase regard their mothers as their role models because of the intimate relationship they create for them. They enjoy the company of their mothers. Children take particular pleasure in listening to their favourite stories presented by their mothers in the same terms, with the same gestures and modulations of voice. It is the responsibility of mothers to prepare children emotionally, physically and intellectually for entry into the school situation. entry into the school situation.

Going to school, which occurs when the child is about seven years old, marks a dramatic change in the lives of all African children. According to Mwamwenda (1995:21) this is the greatest change from the African child's previous life, for in many cases he/she has to learn in a strange language and his/her teacher is often a member of a different society

\subsection{Affective dimension in Tsonga culture}

Among the Tsonga people, education is also mainly the responsibility of the mother. The Tsonga mother always makes the major child-rearing and disciplinary decisions when the father is absent from home.

With regard to children in the Foundation Phase, the affective upbringing is the same in Tsonga families as in African communities generally. In African culture, irrespective of being urbanised or not, impoverished or not, educated or not, the kind of warmth, love and support given by parents shows little difference.

\section{Normative Dimension}

\subsection{General principles}

The normative relationship between parents and children should be motivational rather than of a harsh disciplinary nature. Such a relationship in the family would enable parents to be kind and not harsh to children, to be strict but not authoritative, and children in turn would not like to shame their parents. If children are brought up in this manner, and if they want to do something, they would rather wait their turn. Principles of threat and and physical punishment should not be regarded as a form of motivation because it can be cruel, harmful and damaging to growing children. In a situation where parents are mostly absent, the ansences can constitute a form of neglect because sblings would not care whether the child does right or wrong. According to Chasdi (1994:121), the motivational value of personal interest, encouragement and praise should always prevail and be positive in the family.

Children in the Foundation Phase should be given praise when they have done the right thing and should be reprimanded when doing wrong. They are taught the rules, principles, morals and values that are important to the society in which they live. Chasdi (1994:135) emphasises that in those societies where parents believe that their own actions, rather than fate or heredity, have some effect upon the moral development of the moral developmentof their children, the value system of the culture will be an important part of what is consciously and intentionally transmitted to the child.

During the Foundation Phase, parents at home teach their children how to deal with conflicts and new situations and to take responsibility for their actions and their lives, for example, how to react when reprimanded, and how to communicate appropriately with people. Parents also teach their children about their religious faith. If religious faith is exercised and followed as required in the family, children will grow up obeying their faith.

Rosa (1995:14) declares that personal religion means a faith and hope to which the child can cling during the uncertainties and vicissitudes of his development.

There must be a sound parent-child relationship in the family for children to learn that they are responsible for the fulfilment of their own and others' needs. Discipline is a means of teaching the child self-control and self-direction, which in turn sharpens the child's conscience regarding right and wrong. Chasdi (1994:136) emphasises that the nature and extent of normative upbringing provided by parents can affect the children's becoming, learning and self-concept.

\subsection{Effect of problems/inadequacies}

Parents should always strive for a healthy relationship in the family. If, for instance, parents quarrel in front of their children, the children may no longer have confidence in them and may experience a feeling of insecurity. If the children are not taught the good morals, they may not grow up in a norm-abiding way and if they are not disciplined when they have done wrong, they may become dishonest because of the negative upbringing. 
The poor socio-economic status of some families in the African community tends to jeopardise the moral development of children. For example, material problems and retrenchments being experienced bt their, could cause even less interaction within the family itself. Such conditions can literally cause misbehaviour in the growing children. It may cause children to become lazy about schoolwork and they may even become liars because of the situation which does not change. Sometimes children from such a family environment do not attend school regularly, at times they hide or return on the way bcause of the hopeless feelings they experience.

Some African parents work long hours and some do very hard physical labour which causes fatigue or a degree of despair. Such parents may not have the emotional energy to give support to their children, which in turn may cause the children to misbehave. According to the researcher's observation, most children in the African community accept what comes from parents, as they do not question the instruction up to the age of ten.

Children in the Foundation Phase need to be taught to respect others and obey rules and regulations, because if the instruction is inadequate, poor performance may result.

Inadequate normative guidance of the Foundation Phase children could strongly affect their learning in the sense that some values may be beyond the children's comprehension. Therefore, when dealing with religious aspects, they should not be too critical and judgemental.

\subsection{Principles in the African community/culture}

By nature man is a moral being (Mbiti 1975:116; Vilakazi 1998:27). Religious faith is important in the African community. According to Mbiti (1975:117), an African child not only continues the physical line of life, being in some societies thought to be a re-incarnation of the departed, but also becomes the intensely religious focus on keeping the parents in their state of persnal immortality.

In the African community, the father's responsibility is to manage and oversee his family and act as representative in the broader society, even though he may not be working from home. Lindgren (1969, in Nesengani 1990:15) declares that the African father is the most available model of what is expected from the child in the outside world. The father is the economic provider while themother becomes the guide in the family. According to Rosa (1995:16), the father-absent child in the African family will be unable to bridge the gap between himself and society and he may feel alienated from the society of which he is a part. Rosa further emphasises that paternal deprivation in the African culture can lead to conflicts and rigidities in the individual's sex role adjustment, which in turn is often related to deficits in emotional, cognitive and interpersonal functioning.

Just as God made the first man, a God's man in African culture, therefore, it is believed that man himself makes the individual who becomes the social man. For Africans, the individual is immersed in a religious participation which starts before birth and continues after his death. For him and for the larger community of which he is part, to live is to be caught up in a religious drama. It is, therefore, necessary in the African culture that, as soon as children start school, they are taught to obey religious faith and they learn that man lives in a religious universe. According to Mbiti (1975:15)), both the world and practically all man's activities in it are seen as experienced through a religious understanding and meaning.

According to Gumede (1990:210) there are rules and regulations that are guidelines for living that permeate African culture. Vilakazi (1998:28) emphasises that these rules and regulations are unwritten laws handed down from father to son, from the dim past of African history by word of mouth. Taboos permeate every aspect of the African life from birth to death. Health and its significance is explained along life events and ill-luck that would befall the careless individual as, for example, in living one's hair to be blown about by the wind, eating while standing, or eating in the dark. Sebidi (199:15) echoes that through taboos, African parents teach their children the African code of living. Africans believe that there is a symbolic relationship between the individual and his/her environment (Vilakazi 1998:32) and if an individual should travel to another region without being strengthened beforehand, he/she would become ill as he/she is not adapted to the new atmospheric and environmental conditions.

\subsection{Normative dimension in Tsonga culture}

In some Tsonga families there is still an ancestral belief that the ancestors are like 'angels' who are allocated different duties by the Creator. The angels keep intimate relationship with their families and their primary concern is with the welfare of their descendants. According to Vilakazi (1998:16), these Tsonga families believe that the ancestors are omnipresent, although there is also the idea that they live in their own society, under the earth or in the sky. The belif held by these Tsonga families is tha the ancestral family structure is formed in a hierarchy, which embodies a family lineage with the elders and seniors occupying the authoritative position. 
It is the duty of parents to develop in their children a character that reflects their faith and also include good manners, etiquette, politeness, hospitality, neatness and generosity. In the Tsonga families, just as in any African family, the time for teaching the children is non-stuctured. The Tsonga children are non-structured. The Tsonga children are taught that as King, God is also Lord and Master. God is given these titles in many Tsonga families who are religiously inclined, indicating that all respect and honour are due to Him and man's attitude to Him is one of humbleness and submissiveness.

\section{Cognitive Dimension}

\subsection{General principles}

Parents knowingly or unknowingly are constantly helping children to acquire an educational foundation.

Parents do this by unfolding the reality of the living world for the the child. The more the child is encouraged to follow through on his curiosity, the more likely it is that he will become an imaginative reader and learner. According to Meadows (1996:22), the learning child learns not only how to do the particular task, but also how to observe, analyse, imitate, monitor and review other people and one's own activities. The child in the Foundation Phase should also when it is time to do homework, and when it is time to play.

Meadows (1996:23) declares that cognitive development is to be understood in terms of the child being being implicitly and explicitly trained to behave in ways which the particular culture has developed as cognitively useful. By so behaving, and by practising and reflecting on what is being done, the child internalises the cognitive skills of the culture and can develop them and pass them on to the next generation. Children are helped by the adults in the appropriation of the knowledge and ways of thinking that preceding generations have constructed. Meadows(1996:23) emphasises that the skills required by the children include observation, imitation, generalisation and decontextualisation, all of which develop under the fostering support of social interaction.

\subsection{Effect of problems/inadequacies}

If parents are deficient in their role of guiding their children's cognitive development, it may affect the progress of their children at school. On the other hand, unnecessary punishment, over-reacting and too much worrying about the future of their children, fearing that, if they get anything wrong in their books they might fail at the end of the year, continuous reminder that, if their children do not revise the work and do some corrections, they might have no future, could cause a virtually unbearable burden during the Foundation Phase. Some parents might even do the work for their children because of the fear that their children would fail. However, the parents' cognitive role should rather be to give cognitive support to their children by showing them how to solve problems and how to work with others in a group

According to Kurtz, Gaudin, Wodarski and Howing (1993:588), cognitive development depends heavily on the ongoing quality of the parent-child interaction. The unavailable, neglectful parent present a direct threat to the intellectual development of the child. Low educational aspirations, lack of encouragement to learn, a paucity of language stimulation, non-paricipation in school activities, and unresponsiveness to children's achievements affect success in school and further cognitive development. Wentzel and Erdley (1993:321) sress the importance of the parent-child relationship in influencing cognitive development, stating that parents's atyle of discipline affects children's social and emotional development, which again contributes to their academic, intellectual and cognitive development. Meadows (1996:46) adds that children with less experience of being read to at home tend to exhibit somewhat poorer knowledge of literacy as they begin school and to make slower progress in learning to read. Scarborough and Dobrich (1994:245-347) reviewed a large body of research and found that there is a moderate and fairly consistent association between reading to Foundation Phase school children and the development of skills of literacy and of language.

Social structures play an important role in children's interpersonal relationships. Children who lack such necessary social structures may become predisposed to becoming social isolates. Such children may not have the necessary social cognitive structures that would enable them to interact successfully with their peers and others. Children who lack the necessary social skills to enable them to accommodate and assimilate elements in a new social environment may experience what Piaget calls a social disequilibrium, resulting in social isolation. Strommen (1977, in Budhal 1998:22) declares that early peer relationships are a source of the development of social accommodation and social cognition, which in turn, are the basis for the changing quality of children's relationships. Children's inability to achieve decentration can restrict their social development. In a social situation, children who do not have the capacity to realise that other people's views can be different from theirs may find find themselves in a conflict situation. It is the role of the It is the role 
of parents to help children adapt to to any situation

\subsection{Principles in the African community/culture}

During the Foundation Phase, children in the African community interact less with their peers, but they spend more time playing with older children and sharing ideas with them. African children engage willingly and enthusiastically in discussing topics with older children. In this way, they learn to use different cognitive skills and learn more from older children. African chilldren are taught not to adults too many questions. When watching TV or listening to the radio, the focus should be on what they see or hear and questions should follow later. Most of the African parents do not allow questions - often because some of them may be challenging.

It was observed that a few African parents are not willing to contribute actively to their children's education. For example, they are unable to carry out schoolwork at home with their children, and and very few spend a little time reading books and interpreting these to their childre. Very few African parents can manage to buy magazines which contain educational activities. Finally, the minority of African parents ask their children about pictures in the books and things they have seen. Reading stories to their children and asking them to also read after them promotes cognitive development, especially, the development of language. Colletta (1977, in Kgasoe 1995:3) declares that if African parents could cooperate in supporting their children's education, the self-concept of both children and parents would improve and children would become better achivers.

African children participate in learning mainly because of the great amount of interaction between them and older children. Owens (2001:383) emphasises that learner participation, no matter what the age or colour of the learner, is very important in all education. According to Coughlam (2006), participation increases self-esteem and personal control in the lives of children, young people and families, and fostres mutual respect and shared responsibilities. It is empowering.

\subsection{Cognitive dimension in Tsonga culture}

Cognitive skills development is important in the lives of all growing children. The Tsonga children receive their introduction to language as an instrument of communication and learning at the mother's knee. According to Kgasoe (1995:11), they learn the names of food, utensils and objects in the immediate home environment. During the Foundation Phase, the Tsonga children are introduced to the world beyond the homestead, so as to become active participants in the world in which they find themselves. In some Tsonga families some of the oral tradition could not be found any longer.

According to Mwamwenda (1995:109), it is a common practice among many Tsonga people that children use their right hands for greeting people, eating and passing objects to other people. According to the researcher's observation, such experience, it can be assumed, facilitates children's knowledge of the distinction between the right and left hand.

Hand.

\section{References}

Berger, E.H. 1990. Parents as partners in education. The scool and home working together. New York: Merril Publishing Company.

Bodibe, L. 1990. Traditional Healing and Western therapeutic approaches_Adversaries or reluctant Neighbours. In J. Mason, J Rubenstein \& S. Shuda. (Eds.). From diversity to healing. Durban: South African Institute for Mental and Family Therapy.

Bruner, J. 1990. Acts of Meaning. Cambridge MA: Harvard University Press.

Budhal, R. S.1998. The socially isolated child at school. Unpublished D.Ed Thesis.Pretoria: University of Pretoria.

Chasdi, E.H. 1994. Culture and Human Development. New York: Cambridge University Press.

Cooper, D.C. 1991. The foundations of affective development: Proactive involvement of the Educational psychologist. M.Ed Dissertation. Pretoria: University of Pretoria.

Coughlam, J. 2006. Guide to developing a participation strategy for children, young people and Families: For services across Hampshire Country Council, March 2006.

Etaugh, C. \& Rathas, S. A. 1995. The World of children. New York: Harcourt Base Publishers.

Gumede, M.V.1990. Traditional Healers and Traditional Healing (Untapped resources). Johannesburg: Skotaville.

Jensen,E. 1995. Brain-based learning and teaching. South Africa: Lead the field Africa.

Kgasoe, M.S. 1995. Parental involvement in the education of primary school in the Makapanstad Circuit of the former Bophuthatswana. M.ED Thesis: University of Bophuthatswana.

Kurtz, P.D., Gaudin, J.M., Wodarski, J.S \& Howing, P.T. 1993. Maltreatment and school-aged Child: School performance consequences. A Child Abuse and Neglect, 17(5): 588.

Matlou, R.E. 1993. Parental responsibility and educative teaching in Bophuthatswana Schools. M.ED Fundamental Pedagogics. Pretoria: University of Pretoria. 
Mbiti, J. S. 1975. Inroduction to African religion. London: Heineman Press.

Meadows, S. 1996. Parenting behaviour and children's cognitive development. U.S.A.: Psychology Press.

Mwanwenda, T.S. 1995. Educational Psychology. An African perspective, (2nd ed.). Durban: Butterworths.

Nesengani, R. I. 1990. Father-absence and the academic achivement of high school students: M.Ed Dissertation. Cape town: University of Cape Town.

Nhlapo, R.V. 1997. The role of parents. M.Ed Mini Dissertation. Johannesburg. Rand Afrikaans University.

Owens, R.E. 2001. (Jr.). 2001. Language Development: An introduction. Boston: Allyn \& Bacon.

Pienaar, D \& Spoelstra, H. I. 1991. Negotiations, Strategies and Skills. Cape town: Juta \& Company.

Rosa, C.M. 1995. The influence of parental involvement, discipline and choice of values on the scholastic achievement of secondary school pupils with special reference to the father. M.Ed Dissertation. Pretoria: University of South Africa.

Scaborough, H. S. \& Dobrich, W. 1994. On the efficacy of reading to preschoolers. Developmental Review, 14: 245-302.

Sebidi, L. 1999. Dynamics of culture. Tribune (June): 54. African Renaissance Series.

Shaffer, D.R.1993. Developmental Psychology: Childhood and adolescence, (3rd ed.). U.S.A: Cole Publishing Company.

Schlebush, L. 1990. An overview of bridging the mind-body dichotomy within health-care system. In L. Schlebush (Ed.). Clinical Health Psychology. Johannesburg: Soutern Book Publishers, p. 145.

Slavin, R.E. 1991. Educational Psychology: Theory and Practice, (3rd ed.). Massachusetts: Allyn \& Bacon Inc.

Vilakazi, Y.S. 1998. Health seeking behaviour in African families: The role of cognitive schemata in decision-making. M.Ed Dissertation. Pretoria: University of Pretoria.

Wyngaard, A.T. 1994. Child and Society: A socio-pedagogical perspective, (1st ed.). Durbanville. South Africa: Wachwa Publishers. 